\title{
Posttranscriptional and transcriptional regulation of endothelial nitric-oxide synthase during hypoxia: the role of microRNAs
}

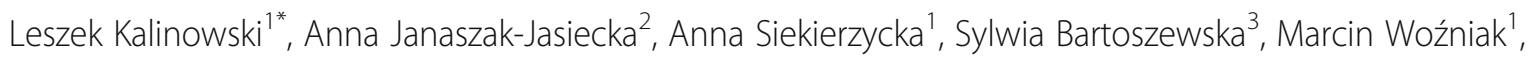
Dawid Lejnowski ${ }^{2}$, James F. Collawn ${ }^{4}$ and Rafal Bartoszewski ${ }^{*}$ (i)

\author{
* Correspondence: \\ lekal@gumed.edu.pl; \\ rafalbar@gumed.edu.pl \\ 'Department of Medical Laboratory \\ Diagnostics and Central Bank of \\ Frozen Tissues \& Genetic \\ Specimens, Medical University of \\ Gdansk, Debinki 7, 80-211 Gdansk, \\ Poland \\ ${ }^{2}$ Department of Biology and \\ Pharmaceutical Botany, Medical \\ University of Gdansk, Hallera 107, \\ 80-416 Gdansk, Poland \\ Full list of author information is \\ available at the end of the article
}

\begin{abstract}
Understanding the cellular pathways that regulate endothelial nitric oxide (eNOS, NOS3) expression and consequently nitric oxide (NO) bioavailability during hypoxia is a necessary aspect in the development of novel treatments for cardiovascular disorders. eNOS expression and eNOS-dependent NO cellular signaling during hypoxia promote an equilibrium of transcriptional and posttranscriptional molecular mechanisms that belong to both proapoptotic and survival pathways. Furthermore, NO bioavailability results not only from eNOS levels, but also relies on the presence of eNOS substrate and cofactors, the phosphorylation status of eNOS, and the presence of reactive oxygen species (ROS) that can inactivate eNOS. Since both NOS3 levels and these signaling pathways can also be a subject of posttranscriptional modulation by microRNAs (miRNAs), this class of short noncoding RNAs contribute another level of regulation for NO bioavailability. As miRNA antagomirs or specific target protectors could be used in therapeutic approaches to regulate NO levels, either by changing NOS3 mRNA stability or through factors governing eNOS activity, it is critical to understand their role in governing eNOS activity during hypoxa. In contrast to a large number of miRNAs reported to the change eNOS expression during hypoxia, only a few miRNAs modulate eNOS activity. Furthermore, impaired miRNA biogenesis leads to NOS3 mRNA stabilization under hypoxia. Here we discuss the recent studies that define miRNAs' role in maintaining endothelial NO bioavailability emphasizing those miRNAs that directly modulate NOS3 expression or eNOS activity.
\end{abstract}

Keywords: eNOS, ER stress, Hypoxia, miRNA, Nitric oxide, NO bioavailability, NOS3, SONE

Abbreviations: 3'- UTR, 3'-untranslated region; eNOS, NOS3 - endothelial nitric oxide synthase; HIF, Hypoxia-inducible factor; hnRNP L, Heterogeneous nuclear ribonucleoprotein L; HRE, Hypoxia-response element; miRNA, microRNA; NO, Nitric oxide; $\mathrm{O}_{2}^{-}$, Superpoxide; $\mathrm{ONOO}^{-}$, Peroxynitrite; $\mathrm{RISC}$, miRNA-induced silencing complex; VEGF, Vascular endothelial growth factor; VEGFR2, Vascular endothelial growth factor receptor-2; VHL, Gene encoding von Hippel-Lindau tumor suppressor protein

\section{Biomed Central}

(c) 2016 The Author(s). Open Access This article is distributed under the terms of the Creative Commons Attribution 4.0 International License (http://creativecommons.org/licenses/by/4.0/), which permits unrestricted use, distribution, and reproduction in any medium, provided you give appropriate credit to the original author(s) and the source, provide a link to the Creative Commons license, and indicate if changes were made. The Creative Commons Public Domain Dedication waiver (http://creativecommons.org/ publicdomain/zero/1.0/) applies to the data made available in this article, unless otherwise stated. 


\section{Introduction}

The signaling molecule nitric oxide (NO) produced in endothelium by nitric oxide synthase 3 (eNOS, encoded by NOS3 gene) plays a pivotal role in the maintenance of homeostasis in the blood vessel wall [1-3]. eNOS produces nitric oxide through conversion of L-arginine and oxygen into L-citrulline and NO [4]. Rapid NO diffusion to vascular smooth muscle cells leads to guanosine 3,5-cyclic monophosphate formation and consequently vasodilation [4]. Hence, impaired activity of eNOS and the loss of NO bioavailability are associated with endothelial cell dysfunction that is an independent risk factor for cardiovascular diseases [1,2]. Endothelium dysfunction due to the reduction of $\mathrm{NO}$ bioavailability in the vessel wall is one of the earliest manifestations of atherosclerosis and hypertension [5]. Although eNOS targeting is an attractive approach in terms of preventing and treating atherosclerosis and other cardiovascular disorders, the phenomenon of eNOS uncoupling hampers the attempts to assess whether eNOS-derived NO serves to protect vessels from the progression of atherosclerosis. eNOS must be regarded as both an $\mathrm{NO}$ and an $\mathrm{O}_{2}^{-}$-producing enzyme, and therefore, eNOS may have dual effect on vascular function, depending on its functional state [6-11]. Hence, future therapeutic approaches should rely on the physiologically relevant restoration of endothelial NO homeostasis via modulation of eNOS activity rather than just overexpression of this enzyme.

In endothelial cells, NOS3 is constitutively expressed. NOS3 message, however, is strongly susceptible to upregulation by many factors including: ROS [12]; laminar and oscillatory shear stress [13, 14], and cell growth [15]. The eNOS activity is regulated via two mechanisms, calcium/calmodulin binding or phosphorylation by serine/threoninespecific kinase (Akt) [16]. However, different physiological and pathological conditions have been shown to affect NOS3 expression via both the transcriptional [17-19] and post-transcriptional mechanisms [20-23]. Significantly, hypoxia/ischemia is a major cellular stress that has a profound impact on endothelial cell biology, including cardiovascular pathologies. Thus, understanding the molecular mechanisms regulating NOS3 gene expression under low oxygen tension is a high-impact priority. Importantly, prolonged hypoxia and ischemia lower endothelial NOS3 expression, leading to a loss of NO bioavailability [23, 24]. In these instances, a major contributing factor to downregulation of NOS3 expression appears to be a reduction in the stability of NOS3 mRNA. This decrease in NOS3 mRNA abundance is attributed, at least in part, to the destabilization of NOS3 mRNAs by a natural overlapping antisense transcript to NOS3 called $s O N E$ [23]. However during hypoxia, specific miRNAs may reduce endothelial NOS3 levels and consequently modulate the bioavailability of NO [25]. Furthermore, hypoxia often disturbs endoplasmic reticulum (ER) homeostasis, leading to ER stress response activation [26]. Hence, besides hypoxia-related transcription factors and miRNAs, the transcriptional and post-transcriptional mediators (miRNAs) of the ER stress pathway might also influence endothelial NO bioavailability.

\section{Cardiovascular disorders and NO bioavailability}

The endothelium plays a crucial role in regulating vascular function. Although serving as an extremely active endocrine and paracrine organ that produces a large variety of molecules participating in complex biochemical processes, the simple product generated by eNOS - NO - seems to be a key molecule required for the maintenance of 
vascular homeostasis $[1-3,7,8]$. For example, NO produced by eNOS causes vasodilation. Thus, NOS3 knockout mice are hypertensive [27], whereas NOS3 transgenic mice exhibit hypotension [28]. In addition, NO reduces the activation and aggregation of platelets, attenuates adhesion of leukocytes to the endothelium, reduces the permeability of the endothelium, and inhibits proliferation and migration of vascular smooth muscle cells $[29,30]$. Impaired activity of eNOS and the loss of NO bioavailability are associated with endothelial cell dysfunction that is an independent risk factor for cardiovascular diseases $[1,2]$. A number of models of endothelial dysfunction in experimental animals together with clinical data provided evidence that NO bioavailability is reduced by increased production of reactive oxygen species (ROS) in the vessel wall. Of ROS, superoxide $\left(\mathrm{O}_{2}^{-}\right)$is the key molecule as many other ROS are formed secondary to the reactions involving $\mathrm{O}_{2}{ }^{-}$. Because $\mathrm{O}_{2}{ }^{-}$and $\mathrm{NO}$ are both radicals and contain unpaired electrons in their outer orbitals, they undergo an extremely rapid, diffusion limited radical-radical reaction, leading to the formation of peroxynitrite $\left(\mathrm{ONOO}^{-}\right)$, a much stronger oxidant than $\mathrm{O}_{2}{ }^{-}$itself. There is growing evidence that an imbalance between production $\mathrm{NO}$ and $\mathrm{O}_{2}{ }^{-}$within the endothelium can contribute to the onset of a variety of cardiovascular disease states such as atherosclerosis, thrombosis, hypertension, diabetes mellitus, heart failure, post-angioplasty restenosis, cerebral vasospasm and delayed wound healing $[1,2,7,8]$. Many of these disorders are associated with hypoxia or ischemia in different organs and this leads to a decrease in oxygen and nutrient delivery to the tissues. Importantly, hypoxia and ischemia lower endothelial NOS3 expression, leading to loss of NO bioavailability.

\section{eNOS uncoupling}

Because $\mathrm{O}_{2}{ }^{-}$avidly scavenges $\mathrm{NO}$, a reduction of bioactive NO may occur despite an increased NO generation. Among several enzymatic systems that are capable of producing $\mathrm{O}_{2}^{-}$, eNOS itself is a significant source of $\mathrm{O}_{2}^{-}$in the vessel wall $[1,7,9,10,31]$. In the absence of a substrate, L-arginine, or a cofactor such as tetrahydrobiopterin $\left(\mathrm{BH}_{4}\right)$, eNOS synthesizes $\mathrm{O}_{2}{ }^{-}$in preference to NO. In the process of eNOS dysfunction called enzyme "uncoupling", the electron flow through the eNOS enzyme is then diverted to molecular oxygen rather than to L-arginine, which facilitates the production of $\mathrm{O}_{2}{ }^{-}$rather than NO [7-9, 11]. Furthermore, during pathological conditions, eNOS mediates formation of peroxynitrite $\left(\mathrm{ONOO}^{-}\right.$) [32-34]. Hence, the extent of eNOS uncoupling is dependent on $\mathrm{ONOO}^{-}$produced initially in the reaction between $\mathrm{NO}$ produced by eNOS and $\mathrm{O}_{2}{ }^{-}$generated by both $\mathrm{NAD}(\mathrm{P}) \mathrm{H}$ oxidase and eNOS $[35,36]$. It has also been suggested that both the zinc-thiolate center of eNOS and $\mathrm{BH}_{4}$ are probable targets of oxidation by $\mathrm{ONOO}^{-}$[37]. This in turn can lead to dissociation of eNOS dimers to monomers with the subsequent release of zinc cations [38]. Furthermore, cellular studies have shown that phosphorylation of eNOS at specific amino acids (Ser-1177, Thr-495) can regulate enzyme-mediated production of both $\mathrm{NO}$ and $\mathrm{O}_{2}^{-}$[39]. eNOS uncoupling partially occurs even in normal endothelium and may explain the predisposition of some individuals to endothelial dysfunction and cardiovascular complications. Although eNOS targeting is an attractive approach in terms of preventing and treating atherosclerosis and other cardiovascular disorders, the phenomenon of eNOS uncoupling hampers the attempts to assess whether eNOS-derived NO serves to protect vessels from the progression of atherosclerosis. eNOS must be regarded as both an 
$\mathrm{NO}$ and an $\mathrm{O}_{2}{ }^{-}$-producing enzyme, and therefore eNOS may have dual effect on vascular function, depending on its functional state [6-11].

\section{Regulation of eNOS expression during hypoxia}

The molecular basis of hypoxic vasodilation is not fully understood [40] and the various effects of hypoxia on eNOS in endothelial cells have been described previously [24]. Under normoxia, the NOS3 mRNA is highly stable in human endothelium [41]. However, eNOS activity and NOS3 expression levels are increased by hypoxia in some reports [42-46], whereas in others they either decreased or not affected [24, 47, 48]. The discrepancies between these reports result from the duration of exposure to hypoxia as well as from the different endothelial models used. Importantly, the prolonged hypoxia usually causes a decrease in NOS3 expression, while short-term oxygen depletion leads to NOS3 mRNA accumulation in HUVECs (Fig. 1). The early hypoxic induction of NOS3 expression was shown to rely on hypoxia-responsive elements (HRE) at position _5375 to _5366 (relative to the transcription start site) [19]. NOS3 luciferase reporter studies illustrated that both of these HREs were functional for NOS3 promoter activity induction by hypoxia and by HIF-2 overexpression [19]. Hence, during early hypoxia, HIFs and especially HIF-2 have been shown to induce NOS3 expression. Indeed, we previously demonstrated that HIF-1 is induced and accumulates at the early stages of hypoxia in primary endothelial cells and this positively correlates

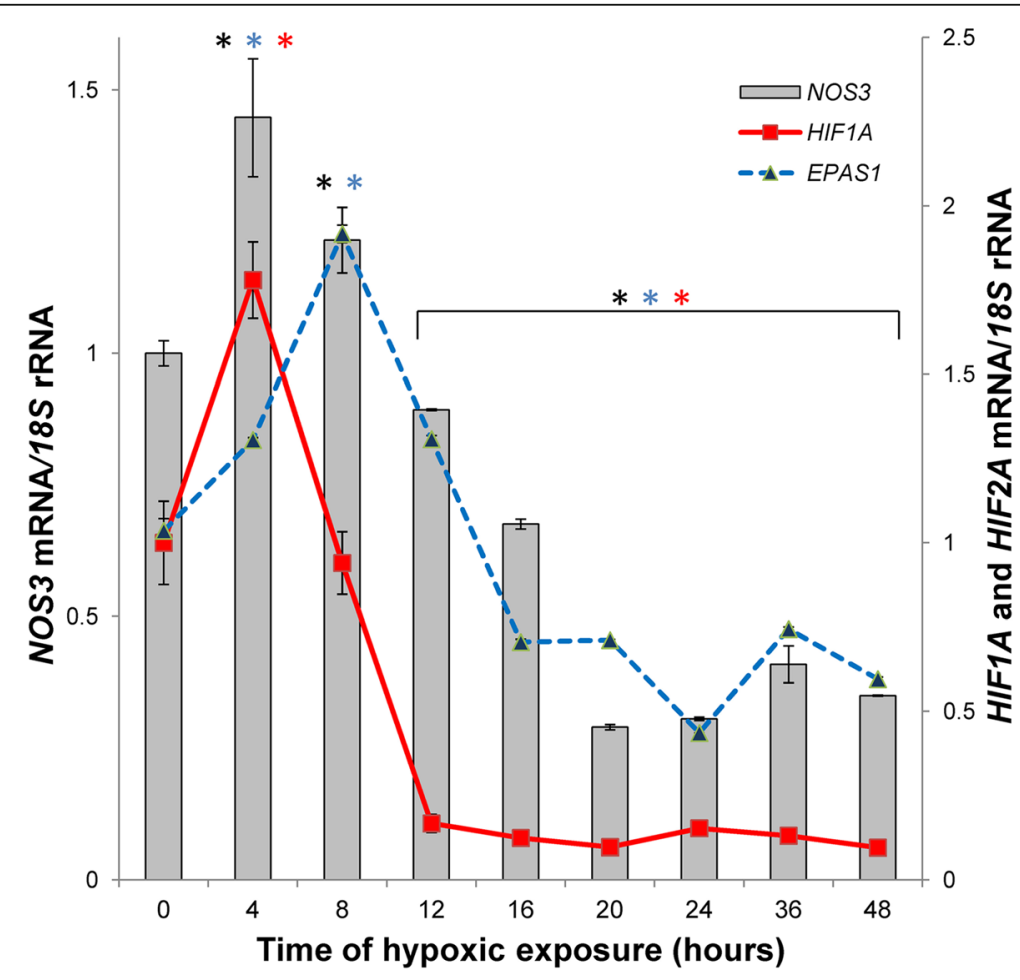

Fig. 1 Hypoxia induces dynamic changes in the mRNA expression profiles of the NOS3, HIF1A and HIF2A (EPAS1) in human human umbilical vein endothelial cells (HUVECs). The mRNA levels during hypoxia were monitored in qRT-PCR experiments as described in [49, 50]. The results from 2 independent experiments $(n=8)$ are plotted normalized to $18 \mathrm{~S}$ rRNA levels and expressed as a fold-change compared to the normoxic control. The hypoxia had no impact on HUVECs viability as monitored with Real Time xCelligence as described in [106]. Error bars represent standard deviations. Significant changes $(p<0.05)$ are marked with an "*" 
with the NOS3 mRNA expression profile [49, 50]. However, the HIF-2 expression increases at later stages of hypoxia [50] correlated with NOS3 mRNA levels, presumably stabilizing NOS3 mRNA. Thus, further studies are required in order to better understand the role HIFs in NOS3 expression modulation in response to hypoxia.

Under prolonged hypoxia, the reduction in stability of the mature NOS3 mRNA is a major contributing factor to down-regulation of NOS3 expression [25]. Notably, numerous studies have shown that hypoxia significantly down-regulates NOS3 mRNA expression in endothelial cells [23, 24]. Furthermore, experimental models of proliferation/injury [51], tumor necrosis factor alpha treatment [52], and exposure to lipopolysaccharide [53] all decrease NOS3 steady-state mRNA expression in endothelial cells. To date, numerous mechanisms responsible for NOS3 mRNA hypoxic reduction have been proposed. The initial studies postulated that NOS3 mRNA destabilization during hypoxia is inhibited by a Rho kinase inhibitor [54]. We have provided clear evidence that Rho GTPase proteins negatively regulates eNOS expression and HMG-CoA reductase inhibitors (statins) upregulate eNOS expression by blocking Rho geranylgeranylation, which is necessary for its membrane-associated activity $[55,56]$. However, recent studies attributed the hypoxic decrease in NOS3 mRNA abundance, at least in part, to the destabilization of NOS3 mRNAs by $s O N E$ (also known as ATG9B, NOS3AS, and APG9L2) [57]. The NOS3 and $s O N E$ genes are arranged in a tail-to-tail orientation on human chromosome $7 \mathrm{q} 36$, and the transcripts for the two genes are complementary for a total of 662 nucleotides (including exon/exon overlap). During normoxia, the $s O N E$ transcript is expressed at very low levels in endothelial cells, whereas NOS3 is highly abundant [25]. Importantly, long-term hypoxia, which downregulates NOS3 mRNA and protein expression, significantly upregulates steady-state levels of $s O N E$ RNA [23]. Importantly, basal expression of NOS3 mRNA is stabilized by the formation of ribonucleoprotein RNP complexes on 3'-UTR cis elements. Recent studies identified heterogenous nuclear RNP (hnRNP) E1, a ubiquitous, multifunctional RNA-binding protein [25], as a major component of these eNOS-stabilizing RNP complexes [25]. Significantly, the stabilization of NOS3 mRNA by hnRNP E1 complexes constitutes a protective mechanism against the posttranscriptional inhibitory effects of the NOS3 antisense transcript $s O N E$ and miRNAs (miR-765) during normoxic conditions [25]. In normoxia, the hnRNP E1 complexes at NOS3 3'-UTR prevent $S O N E$ and miRNA binding. However, hypoxia disrupts hnRNP E1/NOS3 3'-UTR interactions via increased Akt-mediated serine phosphorylation and nuclear localization of hnRNP E1, while hnRNP E1 levels remain constant [25]. Hence, under hypoxic conditions, removal of hnRNP-mediated protection of NOS3 mRNA makes this transcript susceptible to $s O N E$ and miRNAs-related down-regulation.

All of the studies discussed above imply that hypoxic NOS3 mRNA levels are at equilibrium that result from the simultaneous interplay between HIF transcriptional induction of NOS3 promoter and destabilization of NOS3 mRNA. Furthermore, the factors that modulate HIF signaling or $s O N E$ levels, such as miRNAs, could consequently influence NOS3 mRNA expression, and subsequently eNOS protein levels, and thus NO bioavailability.

\section{Hypoxia-related ER stress activation}

Recent studies also provided compiling evidence that disturbed ER function plays a crucial role in a number of hypoxia-triggered endothelial patholophysiological processes leading 
to cardiovascular disorders such as atherosclerosis, ischemic cardiac and peripheral vascular diseases, and neovascularization [58-60]. Hypoxia triggers endothelial ER stress and apoptosis, and induces very low density lipoprotein (VLDL) receptor (VLDLr) expression through HIF-1 transcriptional activity [61]. Since eNOS protein biogenesis occurs in the ER, hypoxia-related ER stress activation could also modulate NOS3 expression at both the transcriptional and posttranscriptional levels [62]. Importantly, chemical ER stress induction was shown to decrease NOS3 mRNA (Fig. 2) via a negative transcriptional effect on the proapoptotic transcription factor C/EBP homologous protein (CHOP, also known as growth arrest and DNA damage gene 153) [63]. CHOP is expressed at low levels during physiological conditions, but is dramatically up-regulated in response to ER stress [64]. CHOP is a major mediator of apoptosis, and has recently been shown to regulate angiogenesis [65]. During the early adaptive stages of ER stress, we observed NOS3 mRNA induction (Fig. 2), suggesting the involvement of another mechanism. In line with this, it was reported that overexpression of active form of proadaptive ER stress transcription factor (XBP1s) upregulates both NOS3 mRNA and protein levels and leads to an increase in NO production [66]. Overexpression of XBP1s increases Akt phosphorylation [67], whereas the phosphorylation of NOS3 by Akt represents a major $\mathrm{Ca}^{2+-}$ independent regulatory mechanism for the activation of eNOS [68].

Hence, the hypoxic activation of ER stress additionally complicates the mechanism for maintaining NOS3 mRNA levels and contributes at least two other important

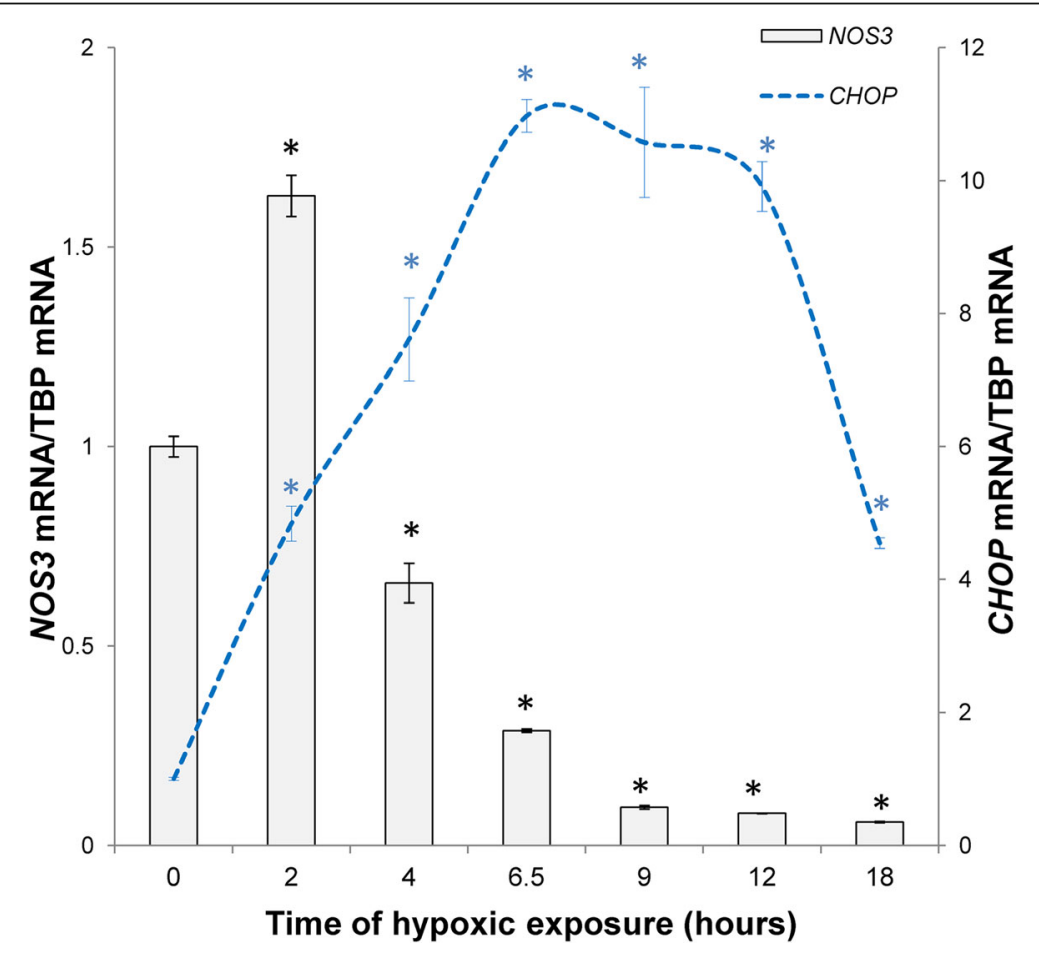

Fig. 2 The ER stress induced dynamic changes in the mRNA of the NOS3 that are negatively correlated with CHOP expression in human umbilical vein endothelial cells (HUVECs). The ER stress was induced with $100 \mu \mathrm{M}$ Calpain Inhibitor I (ALLN). mRNA levels were monitored in qRT-PCR experiments as described in $[106,107]$. The results from 2 independent experiments $(n=8)$ are plotted normalized to TBP mRNA levels and expressed as a fold-change over the untreated control. Error bars represent standard deviations. Significant changes $(p<0.05)$ are marked with an "*" 
transcription factors oppositely modulating NOS3 mRNA abundance - survival XBP1 and proapoptotic CHOP.

\section{microRNAs - Regulation of NO production}

miRNAs are short, single-stranded RNA molecules approximately 22 nucleotides in length that that play key roles in the posttranscriptional regulation of gene expression. As a component of miRNA-induced silencing complex (RISC), miRNAs initiate mRNA decay and thus reduce protein output. The base-pairing interactions between nucleotides 2 and 8 of the miRNA (the seed region) and complementary nucleotides in the $3^{\prime}$-untranslated region (3'-UTR) of mRNA are responsible for the miRNA specificity [69]. Recent studies, however, indicate that miRNAs may play critical roles during hypoxia [70] and ER stress [71].

Despite the fact that inhibiting miRNAs function (through DICER silencing [25]) prevents NOS3 down-regulation during hypoxia, only four miRNAs that directly affect NOS3 expression have been identified that include miR-214 [72], miR-155 [73], miR-24 [74] and miR-765 [25].

miR-214 was reported to be induced in myocardial hypoxia as a indirect result of HIF-1 activity [75]. In Human Umbilical Vein Endothelial Cells (HUVECs), downregulation of miR-214 resulted in increased NOS3 expression (in normoxia) and miRNA binding at NOS3 3'UTR was verified [75]. Hence, the hypoxic induction of miR-214 could be another factor destabilizing NOS3 message.

Direct binding of miR-24 to NOS3 mRNA was confirmed in HUVECs and resulted in lowering eNOS protein levels in normoxia [74]. Although independent studies reported miR-24 induction during hypoxia in human neuroblastoma cells [76], the expression profile of this miRNA during hypoxia in human endothelium requires further study. Recently, it was also proposed that XBP1-related down-regulation of some miRNAs including $m i R-24$, $m i R-125$ and $m i R-214$ may lead to NOS3 mRNA stabilization [66]. However, the role of ER stress and especially ER stress-specific miRNAs in modulating NOS3 mRNA levels requires further study.

miR-155, that is induced during hypoxia in intestinal epithelial cells [77], was also reported to directly bind to NOS3 3'UTR and reduce eNOS levels in human endothelium [73]. miR-765, which is an abundant species (within the top $20 \%$ of all detected microRNAs) in HUVEC [78], binds to NOS3 mRNA at 3' UTR region that is stabilized in normoxia by hnRNP [25]. During hypoxia, however, hnRNP dissociates from NOS3 mRNA sensitizing this transcript to miR-765-dependent degradation [25].

$m i R-155$, miR-214, and miR-24 were reported to destabilize NOS3 mRNA in normoxia via the hnRNP-independent pathway. Therefore changes in these miRNAs expression profiles modulate NOS3 mRNA levels during hypoxia. On the other hand, miR-765 has no effect on NOS3 message in normoxia, while the effects of miR-765 on NOS3 mRNA stability are hnRNP-dependent during hypoxia. Hence, we have example of different mechanisms of miRNA-dependent NOS3 mRNA regulation during hypoxia. The hnRNP-independent pathway allows dynamic and bidirectional modulation of NOS3 mRNA stability up on induction or repression of miRNAs expression during hypoxia. The hnRNP- dependent pathway (also utilized by $s O N E$ ) allows rather 
constitutive downregulation of NOS3 mRNA during hypoxia and does not necessarily require respectful change in miRNAs levels (especially if such a microRNAs are abundant).

Importantly HIF-1, the main transcriptional mediator of cellular responses to hypoxia, promotes the expression of several hypoxamiRs including miR-155 in intestinal epithelial cells [77]. Furthermore, $m i R-155$ has been shown to negatively regulate HIF1A message levels, establishing a negative regulatory feedback loop during hypoxia [77]. Interestingly, the cytokine TNF- $\alpha$, known to dramatically destabilize NOS3 mRNA [79], is also responsible for induction of miR-155 [80]. Thus, miR-155 provides a sensitive link between transcriptional and posttranscriptional mechanisms that regulate NOS3 expression during hypoxia through its actions on HIF-1A and NOS3 mRNA levels.

HIF-1 and HIF-2, therefore, are the perfect candidates for controlling NOS3 expression and NOS3-related cellular signaling during hypoxia. Interestingly, no miRNA has been shown to control $s O N E$ nor HIF-2A levels in human endothelium.

Recently, the hypoxamiR miR-101 was shown to indirectly enhance the interaction between HIF-1 $\alpha$ and Hsp90 that resulted in both increased VEGF expression and eNOS activity [81]. Both HIF-1 and HIF-2 induce proangiogenic vascular endothelial growth factor (VEGF) expression [82]. VEGF subsequently leads to activation of Akt and thus increased NO levels [83, 84]. Furthermore, hypoxia upregulates heat shock protein 90 (Hsp90) expression in endothelial cells [85]: Hsp90 binds to the $\alpha$ subunits of HIF-1, protecting this protein from oxygen-independent degradation and sustaining HIF-1 transcriptional activity [86]. Importantly Hsp90 also increases eNOS activity since it is required for the interaction of eNOS with Akt [87], and Hsp90 binding to eNOS leads to increased affinity for calmodulin binding as well [88].

The other hypoxamiRs that modulate Akt phosphorylation during hypoxia could potentially indirectly affect NO levels as well. To date, numerous hypoxamiRs were shown to regulate Act activity indirectly. $m i R-21, m i R-26, m i R-221 / 222$, and $m i R-486$ bind to phosphatase and tensin homolog deleted on chromosome 10 (PTEN) and, thus activate Akt [89].

miR-21 is induced during hypoxia by HIF-1 and leads to Akt activation [90]. On the other hand, $m i R-26$ is reduced up on oxygen deprivation [91], having potential inhibitory effect on Act activation during hypoxia. Interestingly, although miR-221/222 expression was not reported to be affected by hypoxia, miR221/222 overexpression in Dicer-knockdown endothelial cells restored the elevated eNOS protein levels that was induced by Dicer silencing [92].

Recent reports also provided evidence that $m i R-486$ is upregulated during hypoxia and contributes to VEGF signaling in bone marrow-derived mesynechymal stem cells [93].

HIF-1 drives Importantly, miR-155 that targets mRNA of Src homology-2 domaincontaining inositol $5 \sim$ phosphatase 1 (SHIP1) as well [94]. SHIP1 is a PIP3 phosphatase that deactivates Akt [94]. Hence, miR-155 impacts on NO levels during hypoxia may result from both regulation of NOS3 expression and eNOS activity through Akt. It is possible that miR-155 reduces NOS3 mRNA levels, but at the same time prevents loss of NO via stimulating eNOS activity.

Furthermore, the phosphatidylinositol 3 kinase (PI3K) is the activator of the Akt pathway and is targeted by miR-126 [95], the only miRNA considered to be specially 
expressed in endothelial cells and hematopoietic progenitor cells [96]. Hence, the observed hypoxic downregulation of miR-126 contributes to increased VEGF expression and Akt activation [97].

It has to be emphasized here that hypoxia interactions via increased Akt-mediated serine phosphorylation during hypoxia disrupts hnRNP E1/NOS3 3'-UTR interactions, allowing $S O N E$ - and miR-765-dependent destabilization of NOS3 mRNA [25]. Hence, as best illustrated by $m i R-155$, further studies are required to understand the interplay between the negative effects of hypoxic Act activation on NOS3 levels and the positive effect on eNOS activity.

During hypoxia, oxygen deprivation affects the levels ofthe soluble guanylyl cyclase (sGC) that is the principal receptor for NO, and thus provides another level of regulation of eNOS activity [98, 99]. Importantly, a recent study reported that hypoxia reduces the sGC levels in mice and decreases NO-stimulated sGC activity [100]. The same study that hypoxia induced murine miR-34a-5p to directly downregulate sGC expression, and thus prevent NO signaling [100]. However, whether $m i R-34 a-5 p$ has a similar impact on $\mathrm{SGC}$ in man requires further study.

Another interesting report identified an intronic "27-nt miRNA" derived from the 27-base pair repeats in intron 4 of NOS3 gene [101]. "27-nt miRNA" overexpression indirectly downregulated NOS 3 mRNA and protein expression, and decreased the NOS3 transcriptional efficiency [101]. However, this "27-nt miRNA" expression was not confirmed in human cells nor the specific promoter sequence for this potential miRNA was not identified. Hence, the further studies are required to evaluate the biological function of this miRNA candidate.

The majority of the studies conducted so far have only considered simplified models in which a single miRNA was analyzed in the context of one or more mRNA targets. Although these studies advance our understanding of how miRNAs function as cellular regulators, they neglect the fact that a single mRNA can be regulated by the simultaneous coordinated actions of a number of different miRNAs. For example, the NOS3 3' UTR is 429 base long, the $s O N E$ 3'UTR is 1717 base long), whereas the miRNA seed sequences are usually only 6-8 bases. Hence, NOS3/sONE RNAs can bind a combination of miRNAs simultaneously and these miRNAs will determine NOS3 mRNA's translation and stability. Furthermore, numerous reports conclude the biological role of miRNAs based on correlation studies only or limit their experiments to observing the effects of artificial miRNA overexpression. The latter approach ignores the importance of physiological steady-state levels of miRNAs and theseoften result in the identification of false positive targets.

Hypoxia provides an illustration of the bidirectional impact that miRNAs have on endothelial NO homeostasis. The fact that the very same miRNA simultaneously directly destabilizes NOS3 mRNA and stimulates eNOS activity emphasizes the importance of maintaining the NO balance in both physiological and pathological conditions. This illustrates the need to understand miRNA's role in eNOS biology and particularly with regard to the functional implications. Furthermore, the levels hypoxamiRs often change dynamically during hypoxia $[49,50]$, and thus the temporal effects need to be fully understood.

Interestingly, some hypoxamiRs like $m i R-155$ are also modulated by oxidative stress [102]. Hence, these miRNAs could provide an important sensor of eNOS 
uncoupling and function as a "safety switch". However, validation of this hypothesis requires further study.

It is also worthwhile to note that the endothelium from different vascular beds varies in its molecular responses to hypoxia, including NOS3 and $s O N E$ mRNAs expression, as well as the expression of the miRNAs. Also, the results are often conflicting regarding the changes in miRNA levels during the hypoxia time course [50, 103]. Hence, we speculate that endothelium-related miRNA expression in the different organs can be responsible for the specific eNOS-dependent NO signaling in response to hypoxia/ischemia.

\section{Concluding remarks}

It is clear that understanding the cellular pathways that regulate NO bioavailability in human endothelium under hypoxia is necessary in order to develop novel treatments for cardiovascular disorders. The endothelial NOS3 expression and NO bioavailability during hypoxia results from a complicated equilibrium that exist between the proapoptotic and survival pathways as summarized in Fig. 3. Although the molecular mechanisms of the cellular response to hypoxia and ER stress have been extensively studied, there is limited information regarding their interplay and the role of miRNAs in these processes. Furthermore, a large number of both transcriptional and posttranscriptional factors that maintain endothelial NO homeostasis [104] can also be involved in the miRNAs regulatory networks.

Considering the recent interest in the development of novel micro-RNA-based therapies for human pathologies, it is tempting to speculate that miRNAs or their analogs offer a novel therapeutic approach in regulating endothelial NO bioavailability. Although we can modulate the cellular miRNA levels (either with their analogs (miRNA

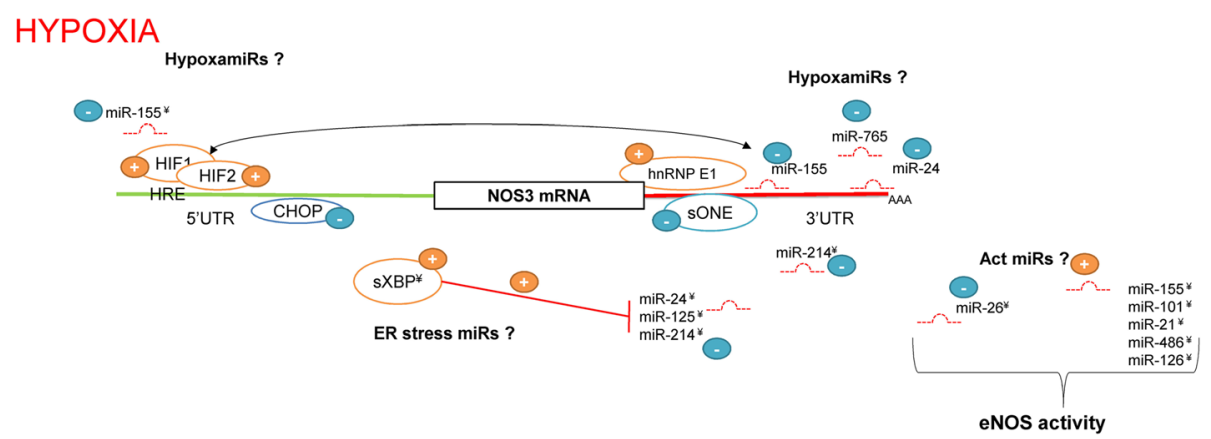

Fig. 3 The transcriptional and posttranscriptional influence of hypoxia on NOS3 mRNA levels. During hypoxia, HIF-1 and HIF-2 accumulate in the nucleus, where they bind to a sequence in the promoter region of NOS3 termed the hypoxia-response element (HRE), and in doing so, induce NOS3 expression. Hypoxia disrupts hnRNP E1/NOS3 3'-UTR interactions and makes this transcript susceptible to SONE and miRNArelated down-regulation. HIF-1 induces miR-155 that along with miR-765 and miR-24 destabilizes NOS3 mRNA. Furthermore, during hypoxia, miR-214 has negative effect on NOS3 expression. Hypoxia is accompanied by deregulation of ER homeostasis and HIF-1-related activation of the ER stress response. The proadaptive and proangiogenic ER stress transcription factor SXBP1 stimulates NOS3 expression transcriptionally and postranscriptionally through reduction of miR-24, miR-125 and miR-214. However, another proapoptotic ER stress transcription factor, CHOP, binds to the $5^{\prime}$ UTR and represses transcription. The hypoxamiRs also modulate Act signaling pathway and consequently eNOS activity. During hypoxia, the changes in the expression levels of miR-155, miR-101, miR-486, miR-21 and miR-126 stimulate Akt activation, whereas miR-26 prevents Act signaling. The (+) expression profile changed during hypoxia contributes to increased expression and activity of NOS3; the (-) expression profile changed during hypoxia has a negative effect on the expression and activity of NOS3; ${ }^{(*)}$ depicts indirect effects on the NOS3 gene 
overexpression) or inhibitors (miRNA reduction), the multiple target genes of miRNAs remain a main limitation of such strategies. Since a single miRNA can regulate hundreds of different mRNAs, an alteration in this miRNA expression pattern will have a wide range of consequences for cell metabolism. miR-155 provides a perfect example how wide and complex potential influence of single miRNA is on eNOS activity. Understanding the miRNA governed balance between decreasing NOS3 expression and increasing eNOS activity is crucial for the development of further therapeutic approaches.

Fortunately, a novel alternative approach relies on target protectors that add specificity to the mRNA of interest. Target protectors are single-stranded, modified RNAs that inhibit the interaction of the miRNA with a specific target without blocking the effects of the particular miRNA on other targets [105]. Hence, target protectors might appear to be extremely helpful tools in sorting out complex role of miRNA in maintaining NO homeostasis. And finally, one has to be aware of the cell- and tissue-specific differences in miRNA expression during hypoxia. Despite these concerns, understanding the role of miRNAs in modulating NO bioavailability will remain an active area of research.

Acknowledgements

Not applicable.

Funding

This study was supported by National Science Centre, Poland, grants N N401 633640 (LK) and 2015/19/B/NZ7/03830 (RB).

Availability of data and materials

Not applicable.

\section{Authors' contributions}

Conceived and designed the experiments: RB. Performed the experiments: AJJ, DL, SB. Analyzed the data: RB, LK, MW. Contributed reagents/materials/analysis tools: RB, LK. Wrote the paper: RB, LK, AS, JC. All authors read and approved the final manuscript.

Competing interests

The authors declare that they have no competing interests.

\section{Consent for publication}

Not applicable.

Ethics approval and consent to participate

Not applicable.

Author details

${ }^{1}$ Department of Medical Laboratory Diagnostics and Central Bank of Frozen Tissues \& Genetic Specimens, Medical University of Gdansk, Debinki 7, 80-211 Gdansk, Poland. ²Department of Biology and Pharmaceutical Botany, Medical University of Gdansk, Hallera 107, 80-416 Gdansk, Poland. ${ }^{3}$ Department of Inorganic Chemistry, Medical University of Gdansk, Gdansk, Poland. ${ }^{4}$ Department of Cell Biology, Developmental, and Integrative, University of Alabama at Birmingham, Birmingham, USA.

Received: 9 June 2016 Accepted: 18 August 2016

Published online: 06 September 2016

References

1. Landmesser U, Hornig B, Drexler H. Endothelial function: a critical determinant in atherosclerosis? Circulation. 2004;109:1127-33.

2. Heitzer T, Schlinzig T, Krohn K, Meinertz T, Munzel T. Endothelial dysfunction, oxidative stress, and risk of cardiovascular events in patients with coronary artery disease. Circulation. 2001;104:2673-8.

3. Channon KM, Guzik TJ. Mechanisms of superoxide production in human blood vessels: relationship to endothelial dysfunction, clinical and genetic risk factors. J Physiol Pharmacol. 2002;53:515-24.

4. Förstermann U, Sessa WC. Nitric oxide synthases: regulation and function. Eur Heart J. 2012;33:829-37.

5. Hadi HaR, Carr CS, Al Suwaidi J. Endothelial dysfunction: cardiovascular risk factors, therapy, and outcome. Vasc Health Risk Manag. 2005;1:183-98.

6. Braam B, Verhaar MC. Understanding eNOS for pharmacological modulation of endothelial function: a translational view. Curr Pharm Des. 2007;13:1727-40.

7. Kalinowski L, Malinski T. Endothelial NADH/NADPH-dependent enzymatic sources of superoxide production: relationship to endothelial dysfunction. Acta Biochim Pol. 2004;51:459-69. 
8. Dobrucki LW, Marsh BJ, Kalinowski L. Elucidating structure-function relationships from molecule-to-cell-to-tissue: from research modalities to clinical realities. J Physiol Pharmacol. 2009;60 Suppl 4:83-93.

9. Kawashima S. The two faces of endothelial nitric oxide synthase in the pathophysiology of atherosclerosis. Endothelium. 2004;11:99-107.

10. Kawashima S, Yokoyama M. Dysfunction of endothelial nitric oxide synthase and atherosclerosis. Arterioscler Thromb Vasc Biol. 2004;24:998-1005.

11. Forstermann U, Munzel T. Endothelial nitric oxide synthase in vascular disease: from marvel to menace. Circulation. 2006:113:1708-14.

12. Zhen J, Lu H, Wang XQ, Vaziri ND, Zhou XJ. Upregulation of endothelial and inducible nitric oxide synthase expression by reactive oxygen species. Am J Hypertens. 2008;21:28-34.

13. Cai H, Mcnally JS, Weber M, Harrison DG. Oscillatory shear stress upregulation of endothelial nitric oxide synthase requires intracellular hydrogen peroxide and CaMKII. J Mol Cell Cardiol. 2004;37:121-5.

14. Davis ME, Cai H, Drummond GR, Harrison DG. Shear stress regulates endothelial nitric oxide synthase expression through c-Src by divergent signaling pathways. Circ Res. 2001;89:1073-80.

15. Searles CD, Miwa Y, Harrison DG, Ramasamy S. Posttranscriptional regulation of endothelial nitric oxide synthase during cell growth. Circ Res. 1999;85:588-95.

16. Fulton D, Gratton JP, Mccabe TJ, Fontana J, Fujio Y, Walsh K, Franke TF, Papapetropoulos A, Sessa WC. Regulation of endothelium-derived nitric oxide production by the protein kinase Akt. Nature. 1999:399:597-601.

17. Ziegler T, Silacci P, Harrison VJ, Hayoz D. Nitric oxide synthase expression in endothelial cells exposed to mechanical forces. Hypertension. 1998;32:351-5.

18. Navarro-Antolin J, Rey-Campos J, Lamas S. Transcriptional induction of endothelial nitric oxide gene by cyclosporine A. A role for activator protein-1. J Biol Chem. 2000;275:3075-80.

19. Coulet F, Nadaud S, Agrapart M, Soubrier F. Identification of hypoxia-response element in the human endothelial nitric-oxide synthase gene promoter. J Biol Chem. 2003;278:46230-40.

20. Yoshizumi M, Perrella MA, Burnett Jr JC, Lee ME. Tumor necrosis factor downregulates an endothelial nitric oxide synthase mRNA by shortening its half-life. Circ Res. 1993;73:205-9.

21. Laufs $U$, Liao JK. Post-transcriptional regulation of endothelial nitric oxide synthase mRNA stability by Rho GTPase. J Biol Chem. 1998;273:24266-71.

22. Searles $C D$, Ide L, Davis ME, Cai H, Weber M. Actin cytoskeleton organization and posttranscriptional regulation of endothelial nitric oxide synthase during cell growth. Circ Res. 2004;95:488-95. doi: 10.1161/01.res.0000138953.21377.80.

23. Fish JE, Matouk CC, Yeboah E, Bevan SC, Khan M, Patil K, Ohh M, Marsden PA. Hypoxia-inducible expression of a natural cis-antisense transcript inhibits endothelial nitric-oxide synthase. J Biol Chem. 2007;282:15652-66.

24. Mcquillan LP, Leung GK, Marsden PA, Kostyk SK, Kourembanas S. Hypoxia inhibits expression of eNOS via transcriptional and posttranscriptional mechanisms. Am J Physiol. 1994;267:H1921-7.

25. Ho JJ, Robb GB, Tai SC, Turgeon PJ, Mawji IA, Man HS, Marsden PA. Active stabilization of human endothelial nitric oxide synthase mRNA by hnRNP E1 protects against antisense RNA and microRNAs. Mol Cell Biol. 2013;33:2029-46.

26. Pereira ER, Frudd $K$, Awad W, Hendershot LM. Endoplasmic reticulum (ER) stress and hypoxia response pathways interact to potentiate hypoxia-inducible factor 1 (HIF-1) transcriptional activity on targets like vascular endothelial growth factor (VEGF). J Biol Chem. 2014;289:3352-64.

27. Huang PL, Huang Z, Mashimo H, Bloch KD, Moskowitz MA, Bevan JA, Fishman MC. Hypertension in mice lacking the gene for endothelial nitric oxide synthase. Nature. 1995;377:239-42

28. Ohashi Y, Kawashima S, Hirata K, Yamashita T, Ishida T, Inoue N, Sakoda T, Kurihara H, Yazaki Y, Yokoyama M. Hypotension and reduced nitric oxide-elicited vasorelaxation in transgenic mice overexpressing endothelial nitric oxide synthase. J Clin Invest. 1998;102:2061-71.

29. Vitiello L, Spoletini I, Gorini S, Pontecorvo L, Ferrari D, Ferraro E, Stabile E, Caprio M, La Sala A. Microvascular inflammation in atherosclerosis. IJC Metabolic \& Endocrine. 2014;3:1-7.

30. Van Haperen R, De Waard M, Van Deel E, Mees B, Kutryk M, Van Aken T, Hamming J, Grosveld F, Duncker DJ and De Crom R. Reduction of blood pressure, plasma cholesterol and atherosclerosis by elevated endothelial nitric oxide. J Biol Chem. 2002;277(50):48803-7.

31. Griendling KK, Sorescu D, Ushio-Fukai M. NAD(P)H oxidase: role in cardiovascular biology and disease. Circ Res. 2000;86:494-501.

32. Vasquez-Vivar J, Kalyanaraman B, Martasek P, Hogg N, Masters BS, Karoui H, Tordo P, Pritchard Jr KA. Superoxide generation by endothelial nitric oxide synthase: the influence of cofactors. Proc Natl Acad Sci U S A. 1998:95:9220-5.

33. Laursen JB, Somers M, Kurz S, Mccann L, Warnholtz A, Freeman BA, Tarpey M, Fukai T, Harrison DG. Endothelial regulation of vasomotion in apoE-deficient mice: implications for interactions between peroxynitrite and tetrahydrobiopterin. Circulation. 2001;103:1282-8.

34. Vasquez-Vivar J, Hogg N, Martasek P, Karoui H, Pritchard Jr KA, Kalyanaraman B. Tetrahydrobiopterin-dependent inhibition of superoxide generation from neuronal nitric oxide synthase. J Biol Chem. 1999;274:26736-42.

35. Kalinowski L, Dobrucki IT, Malinski T. Race-specific differences in endothelial function: predisposition of African Americans to vascular diseases. Circulation. 2004;109:2511-7.

36. Mason RP, Kalinowski L, Jacob RF, Jacoby AM, Malinski T. Nebivolol reduces nitroxidative stress and restores nitric oxide bioavailability in endothelium of black Americans. Circulation. 2005;112:3795-801.

37. Zou M-H, Shi C and Cohen RA. Oxidation of the zinc-thiolate complex and uncoupling of endothelial nitric oxide synthase by peroxynitrite. J Clin Invest. 2002;109(6):817-26.

38. Xu J, Xie Z, Reece R, Pimental D, Zou M-H. Uncoupling of endothelial nitric oxidase synthase by hypochlorous acid: role of NAD(P)H Oxidase-Derived Superoxide and Peroxynitrite. Arterioscler Thromb Vasc Biol. 2006;26: 2688-95.

39. Chen CA, Druhan LJ, Varadharaj S, Chen YR, Zweier JL. Phosphorylation of endothelial nitric-oxide synthase regulates superoxide generation from the enzyme. J Biol Chem. 2008;283:27038-47. 
40. Leach RM, Hill HS, Snetkov VA, Ward JP. Hypoxia, energy state and pulmonary vasomotor tone. Respir Physiol Neurobiol. 2002;132:55-67.

41. Tai SC, Robb GB, Marsden PA. Endothelial nitric oxide synthase: a new paradigm for gene regulation in the injured blood vessel. Arterioscler Thromb Vasc Biol. 2004;24:405-12.

42. Pohl U, Busse R. Hypoxia stimulates release of endothelium-derived relaxant factor. Am J Physiol. 1989;256: H1595-600.

43. Shaul PW, North AJ, Brannon TS, Ujiie K, Wells LB, Nisen PA, Lowenstein CJ, Snyder SH, Star RA. Prolonged in vivo hypoxia enhances nitric oxide synthase type I and type III gene expression in adult rat lung. Am J Respir Cell Mol Biol. 1995;13:167-74.

44. Le Cras TD, Tyler RC, Horan MP, Morris KG, Tuder RM, Mcmurtry IF, Johns RA, Abman SH. Effects of chronic hypoxia and altered hemodynamics on endothelial nitric oxide synthase expression in the adult rat lung. J Clin Invest. 1998;101:795-801.

45. Arnet UA, Mcmillan A, Dinerman JL, Ballermann B, Lowenstein CJ. Regulation of endothelial nitric-oxide synthase during hypoxia. J Biol Chem. 1996;271:15069-73.

46. Hoffmann A, Gloe T, Pohl U. Hypoxia-induced upregulation of eNOS gene expression is redox-sensitive: a comparison between hypoxia and inhibitors of cell metabolism. J Cell Physiol. 2001;188:33-44.

47. Murata T, Yamawaki H, Hori M, Sato K, Ozaki H, Karaki H. Hypoxia impairs endothelium-dependent relaxation in organ cultured pulmonary artery. Eur J Pharmacol. 2001;421:45-53.

48. Toporsian M, Govindaraju K, Nagi M, Eidelman D, Thibault G, Ward ME. Downregulation of endothelial nitric oxide synthase in rat aorta after prolonged hypoxia in vivo. Circ Res. 2000;86:671-5.

49. Janaszak-Jasiecka A, Bartoszewska S, Kochan K, Piotrowski A, Kalinowski L, Kamysz W, Ochocka RJ, Bartoszewski R, Collawn JF. miR-429 regulates the transition between Hypoxia-Inducible Factor (HIF)1A and HIF3A expression in human endothelial cells. Sci Rep. 2016;6:22775.

50. Bartoszewska S, Kochan K, Piotrowski A, Kamysz W, Ochocka RJ, Collawn JF, Bartoszewski R. The hypoxia-inducible miR-429 regulates hypoxia-inducible factor-1alpha expression in human endothelial cells through a negative feedback loop. FASEB J. 2015;29:1467-79.

51. Flowers MA, Wang Y, Stewart RJ, Patel B, Marsden PA. Reciprocal regulation of endothelin-1 and endothelial constitutive NOS in proliferating endothelial cells. Am J Physiol. 1995;269:H1988-97.

52. Yan G, You B, Chen SP, Liao JK, Sun J. Tumor necrosis factor-alpha downregulates endothelial nitric oxide synthase mRNA stability via translation elongation factor 1-alpha 1. Circ Res. 2008;103:591-7.

53. Lu JL, Schmiege 3rd LM, Kuo L, Liao JC. Downregulation of endothelial constitutive nitric oxide synthase expression by lipopolysaccharide. Biochem Biophys Res Commun. 1996;225:1-5.

54. Takemoto M, Sun J, Hiroki J, Shimokawa H, Liao JK. Rho-kinase mediates hypoxia-induced downregulation of endothelial nitric oxide synthase. Circulation. 2002;106:57-62.

55. Kalinowski L, Dobrucki LW, Brovkovych V, Malinski T. Increased nitric oxide bioavailability in endothelial cells contributes to the pleiotropic effect of cerivastatin. Circulation. 2002;105:933-8.

56. Kalinowski L, Dobrucki IT, Malinski T. Cerivastatin potentiates nitric oxide release and enos expression through inhibition of isoprenoids synthesis. J Physiol Pharmacol. 2002;53:585-95.

57. Robb GB, Carson AR, Tai SC, Fish JE, Singh S, Yamada T, Scherer SW, Nakabayashi K, Marsden PA. Posttranscriptional regulation of endothelial nitric-oxide synthase by an overlapping antisense mRNA transcript. J Biol Chem. 2004;279:37982-96.

58. Wu CX, Liu R, Gao M, Zhao G, Wu S, Wu CF, Du GH. Pinocembrin protects brain against ischemia/reperfusion injury by attenuating endoplasmic reticulum stress induced apoptosis. Neurosci Lett. 2013;546:57-62.

59. Salminen A, Kauppinen A, Hyttinen JM, Toropainen E, Kaarniranta K. Endoplasmic reticulum stress in age-related macular degeneration: trigger for neovascularization. Mol Med. 2010;16:535-42.

60. Zhou AX, Tabas I. The UPR in atherosclerosis. Semin Immunopathol. 2013;35:321-32.

61. Yang D, Gao L, Wang T, Qiao Z, Liang Y, Zhang P. Hypoxia triggers endothelial endoplasmic reticulum stress and apoptosis via induction of VLDL receptor. FEBS Lett. 2014:588:4448-56.

62. Gotoh T, Mori M. Nitric oxide and endoplasmic reticulum stress. Arterioscler Thromb Vasc Biol. 2006;26:1439-46.

63. Loinard C, Zouggari Y, Rueda P, Ramkhelawon B, Cochain C, Vilar J, Recalde A, Richart A, Charue D, Duriez M, Mori M, Arenzana-Seisdedos F, Levy Bl, Heymes C, Silvestre JS. C/EBP homologous protein-10 (CHOP-10) limits postnatal neovascularization through control of endothelial nitric oxide synthase gene expression. Circulation. 2012;125:1014-26.

64. Todd DJ, Lee AH, Glimcher LH. The endoplasmic reticulum stress response in immunity and autoimmunity. Nat Rev Immunol. 2008;8:663-74.

65. Silvestre JS. Vascular endothelial growth factor and angiogenesis: the XBP1 games. Circulation. 2013;127:1644-6.

66. Yang J, Zeng L, Wang W, Li Y. Abstract 662: X-box Binding Protein 1 splicing promotes wound healing via modulating endothelial nitric oxide synthase. Arterioscler Thromb Vasc Biol. 2015;35:A662.

67. Zeng L, Xiao Q, Chen M, Margariti A, Martin D, Ivetic A, Xu H, Mason J, Wang W, Cockerill G, Mori K, Li JY-S, Chien S, Hu Y, Xu Q. Vascular endothelial cell growth-activated XBP1 splicing in endothelial cells is crucial for angiogenesis. Circulation. 2013;127:1712-22.

68. Dimmeler S, Fleming I, Fisslthaler B, Hermann C, Busse R, Zeiher AM. Activation of nitric oxide synthase in endothelial cells by Akt-dependent phosphorylation. Nature. 1999;399:601-5.

69. Bartel DP. MicroRNAs: target recognition and regulatory functions. Cell. 2009;136:215-33.

70. Madanecki P, Kapoor N, Bebok Z, Ochocka R, Collawn JF, Bartoszewski R. Regulation of angiogenesis by hypoxia: the role of microRNA. Cell Mol Biol Lett. 2013;18:47-57.

71. Bartoszewska S, Kochan K, Madanecki P, Piotrowski A, Ochocka R, Collawn JF, Bartoszewski R. Regulation of the unfolded protein response by microRNAs. Cell Mol Biol Lett. 2013;18:555-78.

72. Chan LS, Yue PY, Mak NK, Wong RN. Role of microRNA-214 in ginsenoside-Rg1-induced angiogenesis. Eur J Pharm Sci. 2009;38:370-7. 
73. Sun HX, Zeng DY, Li RT, Pang RP, Yang H, Hu YL, Zhang Q, Jiang Y, Huang LY, Tang YB, Yan GJ, Zhou JG. Essential role of microRNA-155 in regulating endothelium-dependent vasorelaxation by targeting endothelial nitric oxide synthase. Hypertension. 2012;60:1407-14.

74. Zhang W, Yan L, Li Y, Chen W, Hu N, Wang H, Ou H. Roles of miRNA-24 in regulating endothelial nitric oxide synthase expression and vascular endothelial cell proliferation. Mol Cell Biochem. 2015;405:281-9.

75. El Azzouzi H, Leptidis S, Dirkx E, Hoeks J, Van Bree B, Brand K, Mcclellan EA, Poels E, Sluimer JC, Van den Hoogenhof, Maarten MG, Armand A-S, Yin X, Langley S, Bourajjaj M, Olieslagers S, Krishnan J, Vooijs M, Kurihara H, Stubbs A, Pinto YM, Krek W, Mayr M, Martins P aD, Schrauwen P, De Windt L. The Hypoxia-Inducible MicroRNA Cluster miR-199a 214 targets myocardial PPARS and impairs mitochondrial fatty acid oxidation. Cell Metab. 2013;18:341-54.

76. Sun X, Ren Z, Pan Y and Zhang C. Antihypoxic effect of miR-24 in SH-SY5Y cells under hypoxia via downregulating expression of neurocan. Biochem Biophys Res Commun. 2016;477(4):692-9. doi: 10.1016/j.bbrc.2016.06.121.

77. Bruning U, Cerone L, Neufeld Z, Fitzpatrick SF, Cheong A, Scholz CC, Simpson DA, Leonard MO, Tambuwala MM, Cummins EP, Taylor CT. MicroRNA-155 promotes resolution of hypoxia-inducible factor 1alpha activity during prolonged hypoxia. Mol Cell Biol. 2011;31:4087-96.

78. Ho JJD, Metcalf JL, Yan MS, Turgeon PJ, Wang JJ, Chalsev M, Petruzziello-Pellegrini TN, Tsui AKY, He JZ, Dhamko H, Man HSJ, Robb GB, Teh BT, Ohh M, Marsden PA. Functional importance of dicer protein in the adaptive cellular response to hypoxia. J Biol Chem. 2012;287:29003-20.

79. Ramseyer V, Hong N, Garvin JL. Tumor necrosis factor alpha decreases NOS3 expression primarily via Rho/Rho kinase in the thick ascending limb. Hypertension. 2012;59:1145-50.

80. Imaizumi T, Tanaka H, Tajima A, Yokono Y, Matsumiya T, Yoshida H, Tsuruga K, Aizawa-Yashiro T, Hayakari R, Inoue I, Ito E, Satoh K. IFN- $\gamma$ and TNF-a synergistically Induce microRNA-155 which regulates TAB2/IP-10 expression in human mesangial cells. Am J Nephrol. 2010;32:462-8.

81. Kim J-H, Lee K-S, Lee D-K, Kim J, Kwak S-N, Ha K-S, Choe J, Won M-H, Cho B-R, Jeoung D, Lee H, Kwon Y-G, Kim YM. Hypoxia-responsive MicroRNA-101 promotes angiogenesis via heme oxygenase-1/Nascular Endothelial growth factor axis by targeting Cullin 3. Antioxid Redox Signal. 2014;21:2469-82.

82. Krock BL, Skuli N, Simon MC. Hypoxia-induced angiogenesis: good and evil. Genes Cancer. 2011;2:1117-33.

83. Michell BJ, Griffiths JE, Mitchelhill Kl, Rodriguez-Crespo I, Tiganis T, Bozinovski S, De Montellano PRO, Kemp BE, Pearson RB. The Akt kinase signals directly to endothelial nitric oxide synthase. Curr Biol. 1999;9:845-S841.

84. Dimmeler S, Dernbach E, Zeiher AM. Phosphorylation of the endothelial nitric oxide synthase at ser-1177 is required for VEGF-induced endothelial cell migration. FEBS Lett. 2000;477:258-62.

85. Almgren CM, Olson LE. Moderate hypoxia increases heat shock Protein 90 expression in excised rat aorta. J Vasc Res. 1999;36:363-71.

86. Isaacs JS, Jung YJ, Mimnaugh EG, Martinez A, Cuttitta F, Neckers LM. Hsp90 regulates a von Hippel Lindauindependent hypoxia-inducible factor-1 alpha-degradative pathway. J Biol Chem. 2002;277:29936-44.

87. Garcia-Cardena G, Fan R, Shah V, Sorrentino R, Cirino G, Papapetropoulos A, Sessa WC. Dynamic activation of endothelial nitric oxide synthase by Hsp90. Nature. 1998;392:821-4.

88. Gratton J-P, Fontana J, O'connor DS, García-Cardeña G, Mccabe TJ, Sessa WC. Reconstitution of an Endothelial Nitric-oxide Synthase (eNOS), hsp90, and Caveolin-1 Complex in Vitro: evidence that hsp90 facilitates calmodulin stimulated displacement of eNOS from Caveolin-1. J Biol Chem. 2000;275:22268-72.

89. Sayed D, Abdellatif M. AKT-ing via microRNA. Cell Cycle. 2010;9:3213-7.

90. Liu L-Z, Li C, Chen Q, Jing Y, Carpenter R, Jiang Y, Kung H-F, Lai L, Jiang B-H. MiR-21 induced angiogenesis through AKT and ERK activation and HIF-1a expression. PLoS One. 2011;6:e19139.

91. Kulshreshtha R, Ferracin M, Wojcik SE, Garzon R, Alder H, Agosto-Perez FJ, Davuluri R, Liu C-G, Croce CM, Negrini M, Calin GA, Ivan M. A MicroRNA signature of hypoxia. Mol Cell Biol. 2007;27:1859-67.

92. Suárez Y, Fernández-Hernando C, Pober JS, Sessa WC. Dicer dependent MicroRNAs regulate gene expression and functions in human endothelial cells. Circ Res. 2007;100:1164-73.

93. Shi X-F, Wang H, Xiao F-J, Yin Y, Xu Q-Q, Ge R-L, Wang L-S. MiRNA-486 regulates angiogenic activity and survival of mesenchymal stem cells under hypoxia through modulating Akt signal. Biochem Biophys Res Commun. 2016:470:670-7.

94. O'connell RM, Chaudhuri AA, Rao DS, Baltimore D. Inositol phosphatase SHIP1 is a primary target of miR-155. Proc Natl Acad Sci. 2009;106:7113-8.

95. Guo C, Sah FJ, Beard L, Willson JKV, Markowitz SD, Guda K. The non-coding RNA, miR-126, Suppresses the growth of neoplastic cells by targeting Phosphatidylinositol 3-Kinase signaling and is frequently lost in colon cancers. Genes Chromosomes Cancer. 2008:47:939-46.

96. Wang S, Aurora AB, Johnson BA, Qi X, Mcanally J, Hill JA, Richardson JA, Bassel-Duby R, Olson EN. An endothelialspecific microRNA governs vascular integrity and angiogenesis. Dev Cell. 2008;15:261-71.

97. Ye P, Liu J, He F, Xu W, Yao K. Hypoxia-induced deregulation of miR-126 and its regulative effect on VEGF and MMP-9 expression. Int J Med Sci. 2014;11:17-23.

98. Martin E, Berka V, Tsai AL, Murad F. Soluble guanylyl cyclase: the nitric oxide receptor. Methods Enzymol. 2005;396: 478-92. doi:10.1016/S0076-6879(05)96041-2. Elsevier Inc.

99. Russwurm M, Koesling D. NO activation of guanylyl cyclase. EMBO J. 2004;23:4443-50.

100. Xu X, Wang S, Liu J, Dou D, Liu L, Chen Z, Ye L, Liu H, He Q, Raj JU, Gao Y. Hypoxia induces downregulation of soluble guanylyl cyclase $\beta(1)$ by miR-34c-5p. J Cell Sci. 2012;125:6117-26.

101. Li Y, Yan L, Zhang W, Hu N, Chen W, Wang H, Kang M, Ou H. Suppression of endothelial nitric oxide synthase expression and endothelial cell proliferation by an intronic 27-ntmiRNA and it's a novel link to AP-1. Am J Transl Res. 2015;7:285-97.

102. Zampetaki A, Dudek K, Mayr M. Oxidative stress in atherosclerosis: the role of microRNAs in arterial remodeling. Free Radic Biol Med. 2013;64:69-77.

103. Lee ST, Chu K, Jung KH, Yoon HJ, Jeon D, Kang KM, Park KH, Bae EK, Kim M, Lee SK, Roh JK. MicroRNAs induced during ischemic preconditioning. Stroke. 2010;41:1646-51. 
104. Searles CD. Transcriptional and posttranscriptional regulation of endothelial nitric oxide synthase expression. Am J Physiol Cell Physiol. 2006;291:C803-16.

105. Staton AA, Giraldez AJ. Use of target protector morpholinos to analyze the physiological roles of specific miRNAmRNA pairs in vivo. Nat Protoc. 2011;6:2035-49.

106. Bartoszewski R, Hering A, Marszall M, Stefanowicz Hajduk J, Bartoszewska S, Kapoor N, Kochan K, Ochocka R. Mangiferin has an additive effect on the apoptotic properties of hesperidin in Cyclopia sp. tea extracts. PLoS One. 2014;9:e92128.

107. Bartoszewski R, Rab A, Fu L, Bartoszewska S, Collawn J, Bebok Z. CFTR expression regulation by the unfolded protein response. Methods Enzymol. 2011:491:3-24.

Submit your next manuscript to BioMed Central and we will help you at every step:

- We accept pre-submission inquiries

- Our selector tool helps you to find the most relevant journal

- We provide round the clock customer support

- Convenient online submission

- Thorough peer review

- Inclusion in PubMed and all major indexing services

- Maximum visibility for your research

Submit your manuscript at www.biomedcentral.com/submit 